\title{
A Short Note on the History of Graph Drawing
}

\author{
Eriola Kruja ${ }^{1}$, Joe Marks² ${ }^{2}$ Ann Blair ${ }^{1}$, and Richard Waters ${ }^{2}$ \\ 1 Harvard University, Cambridge, MA 02138 \\ $\{$ kruja, amblair $\} @ f a s . h a r v a r d . e d u$ \\ 2 MERL - Mitsubishi Electric Research Laboratories, Cambridge, MA 02139 \\ \{marks, waters\}@merl.com
}

\begin{abstract}
The origins of chart graphics (e.g., bar charts and line charts) are well known 30, with the seminal event being the publication of William Playfair's (1759-1823) The Commercial and Political Atlas in London in 1786 [26]. However, the origins of graph drawing are not well known. Although Euler (1707-1783) is credited with originating graph theory in 1736 [12 20], graph drawings were in limited use centuries before Euler's time. Moreover, Euler himself does not appear to have made significant use of graph visualizations. Widespread use of graph drawing did not begin until decades later, when it arose in several distinct contexts. In this short note we present a selection of very early graph drawings; note the apparent absence of graph visualization in Euler's work; and identify some early innovators of modern graph drawing.
\end{abstract}

\section{Early Graph Drawing}

Although geometric drawings of various kinds have been used extensively through the ages, drawings that are visual abstractions of mathematical graph 1 arose relatively recently and have only achieved general currency in the last 150 years.
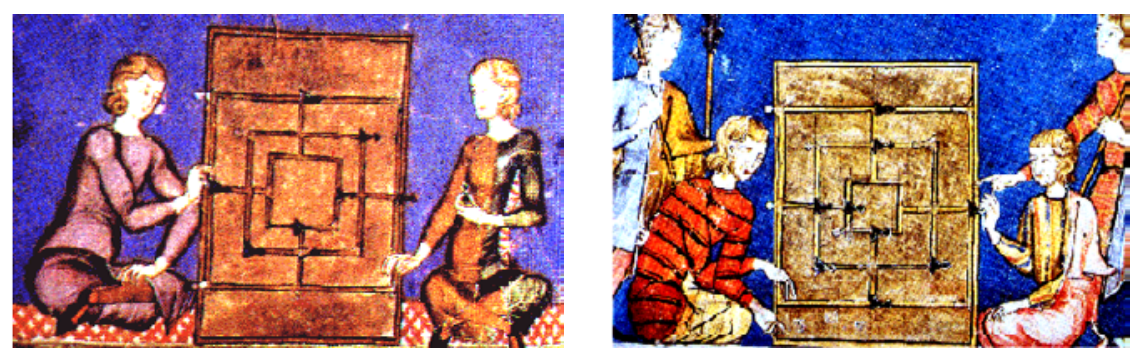

Fig. 1. Depictions of Morris gameboards from the 13th century. The nodes of these graph drawings are the positions that game counters can occupy. The edges indicate how game counters can move between nodes. Reproduced with permission.

\footnotetext{
${ }^{1}$ A mathematical graph consists of a set of nodes and a set of edges. An edge connects a pair of nodes.

P. Mutzel, M. Jünger, and S. Leipert (Eds.): GD 2001, LNCS 2265, pp. 272-286, 2002.

(C) Springer-Verlag Berlin Heidelberg 2002
} 
The earliest forms of graph drawing were probably of Morris or Mill games [35]. Although other early games are based on an underlying notion of a graph, the boards of Mill games depict the graph explicitly (as do some other early games — see [24]). The earliest example of Mill gameboards come from stone carvings in Ancient Egypt. According to Henry Parker ([25], p. 578), they are to be found on roof slabs in a temple began by Rameses I (1400-1366, B.C). Parker describes these carvings in his book, but unfortunately he does not provide any pictures of them. The earliest examples of Mill gameboards to be drawn in a book probably come from the 13th-century "Book of Games," produced under the direction of Alfonso X (1221-1284), King of Castile and Leon [2]. Two of these drawings are shown in Figure 12 35.

The other known examples of ancient graph drawing are family trees that decorated the atria of patrician roman villas. They are described by Pliny the Elder and Seneca, but no examples have survived ([19], p. 111). The earliest surviving examples of genealogical graph drawing are from the Middle Ages [19]. Three examples are shown in Figure 2. The drawing on top, which shows Noah's descendants, is from the 11th century 6] 2 Another religiously inspired genealogy is shown in the bottom left of the figure [8]. In addition to biblical genealogies, family trees of the nobility were popular. The drawing on the bottom right shows a 12th-century genealogy of the Saxon dynasty [34.

Genealogy was not only for religious figures and nobles. Figure 3 contains two sketches of family trees. The top tree is unusual in that it was included in a personal legal document not intended for publication: it was offered as evidence to the Court of Requests during the reign of Elizabeth I by John Stalham to establish his pedigree. He was engaged in a legal dispute over lands and tenements in the parishes of Snelston Alsop and Roston, in the county of Derby, England 28]. The English Public Records Office also contains some pre-Elizabethan examples of sketched family trees in similar legal documents. This usage seems to indicate that educated people understood tree drawings and used them routinely by the 15th century. A later and more extensive family tree is shown at the bottom of Figure 3 It shows the genealogy of the Mannelli family from Florence, Italy, and is one of the earliest and cleanest examples of curved-edge graph drawing 3 . Many more delightful examples of early family trees can be found in the article by Christiane Klapisch-Zuber [19].

Another tree form that appears frequently in medieval literature is one used to depict categories of various kinds. The elegant 14th-century drawing in the left-hand side of Figure 4 shows various cardinal and theological virtues and their more specific subvirtues ([23], p. 30) 3 The less-refined drawing on the right-hand side, also from the 14 th century, categorizes various vices $([23]$, p. 45).

\footnotetext{
${ }^{2}$ The careful reader will note that the graph in the figure is not a tree, which would seem to indicate some anomalies in Noah's family history!

${ }^{3}$ Murdoch provides source references for all of the figures from his book 23] reproduced here. The drawings shown are from manuscripts held by the British Library, London, and the Bibliothèque Nationale, Paris.
} 

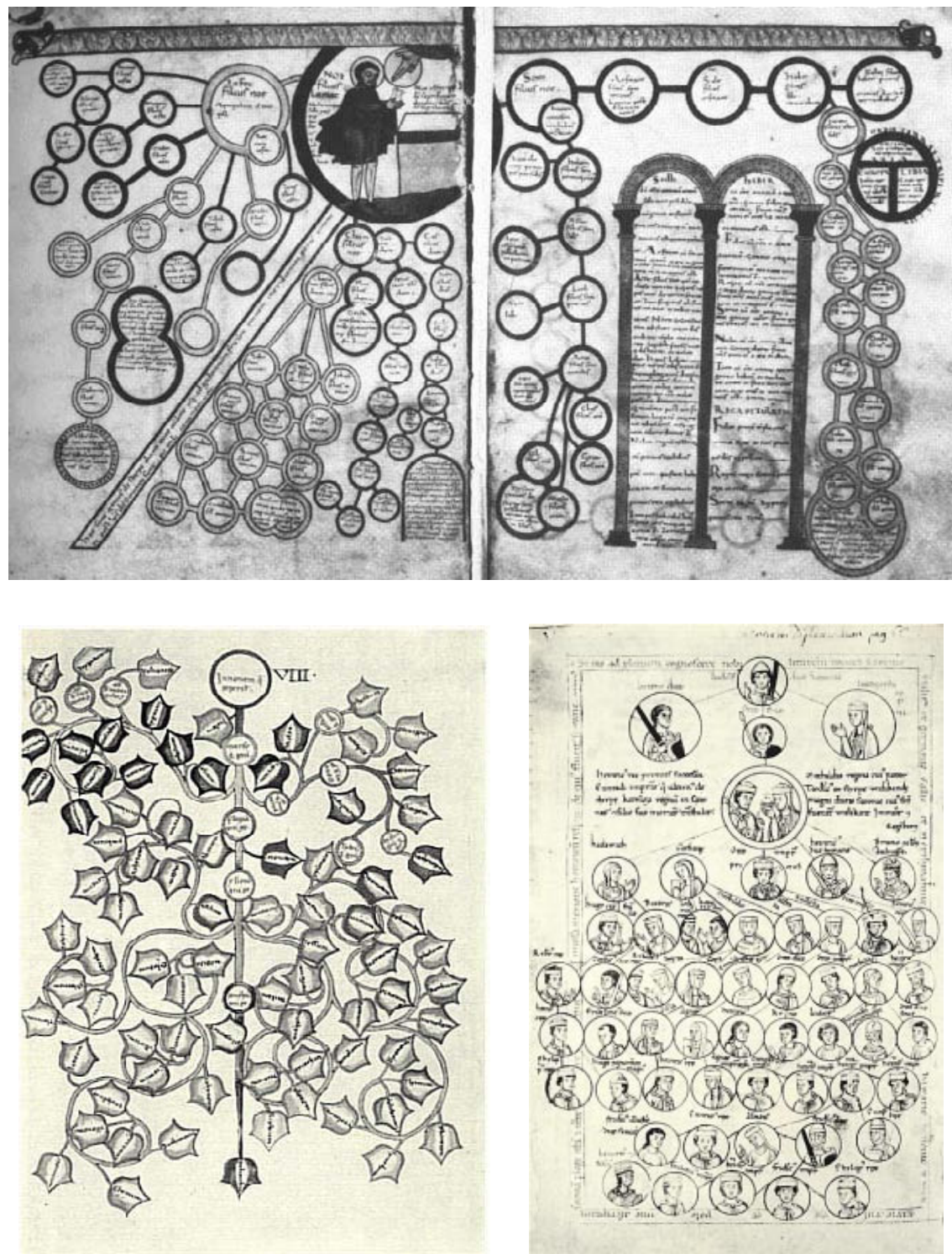

Fig. 2. Family trees that appear in manuscripts from the Middle Ages. Note that the top drawing is spread over two pages in the original manuscript. Reproduced with permission.

Graphs, as opposed to tree drawings, were also used in the Middle Ages to represent and visualize abstract information [23]. For example, certain canonical graph drawings appear regularly in medieval literature. Squares of opposition were pedagogical tools used in the teaching of logic, particularly the relations 

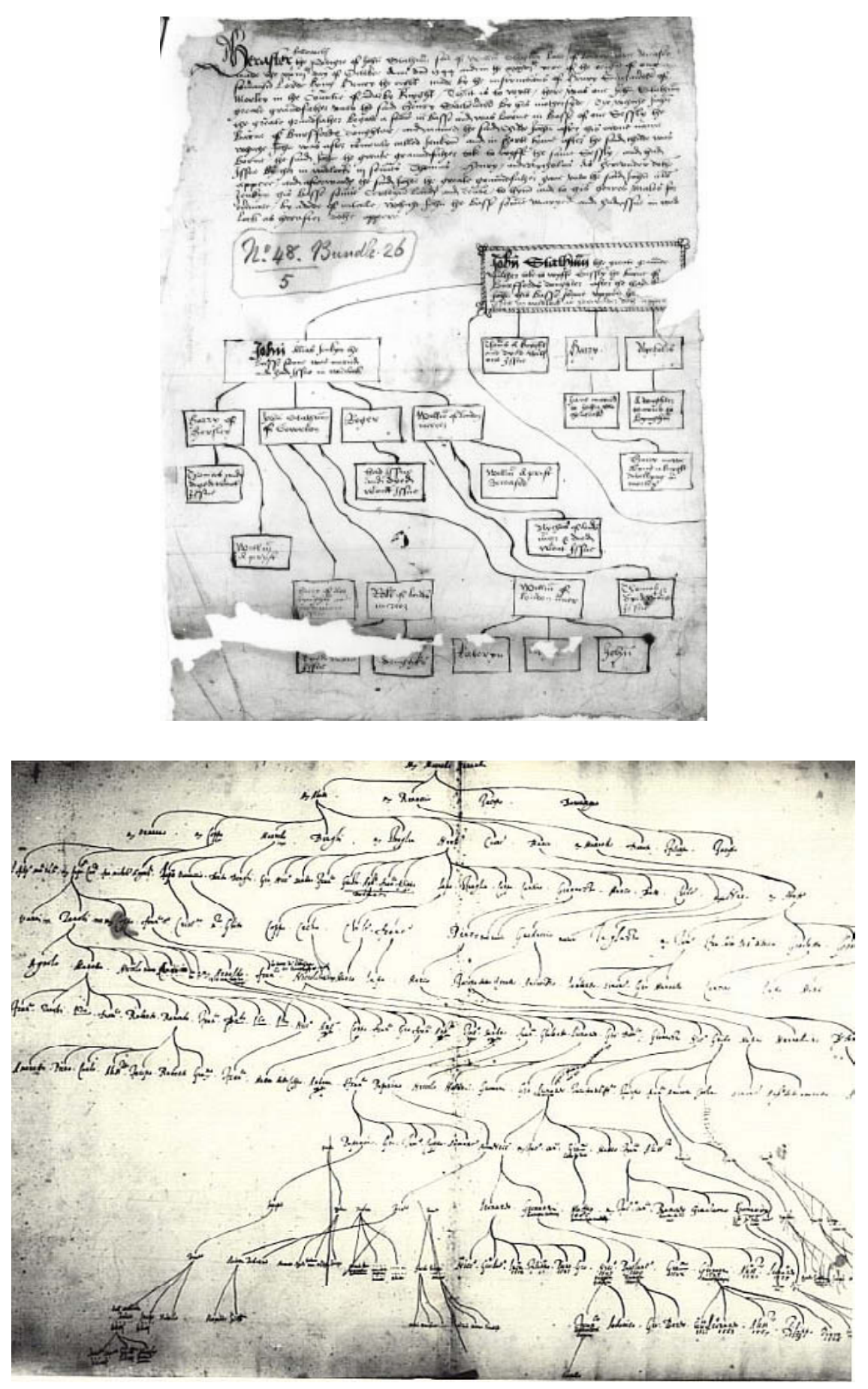

Fig. 3. Family-tree sketches from the 15th and 16th century. Reproduced with permission. 
between propositions or syllogisms. They were designed to facilitate the recall of knowledge that students already had, and hence did not contain complete information. Figure 5 contains a simple example due to the 14th-century French mathematician and philosopher, Nicole Oresme (1323-1382): it depicts a basic argument in Aristotelian natural philosophy ([23], p. 67). A more complex graph drawing that extends the basic form is shown in Figure 6. It is due to a 16thcentury Spanish scholar, Juan de Celaya (1490-1558), who created the drawing to explain a treatise of the 13th-century philosopher and physician Peter of Spain, later Pope John XXI (1215-1277) ([23], p. 65).
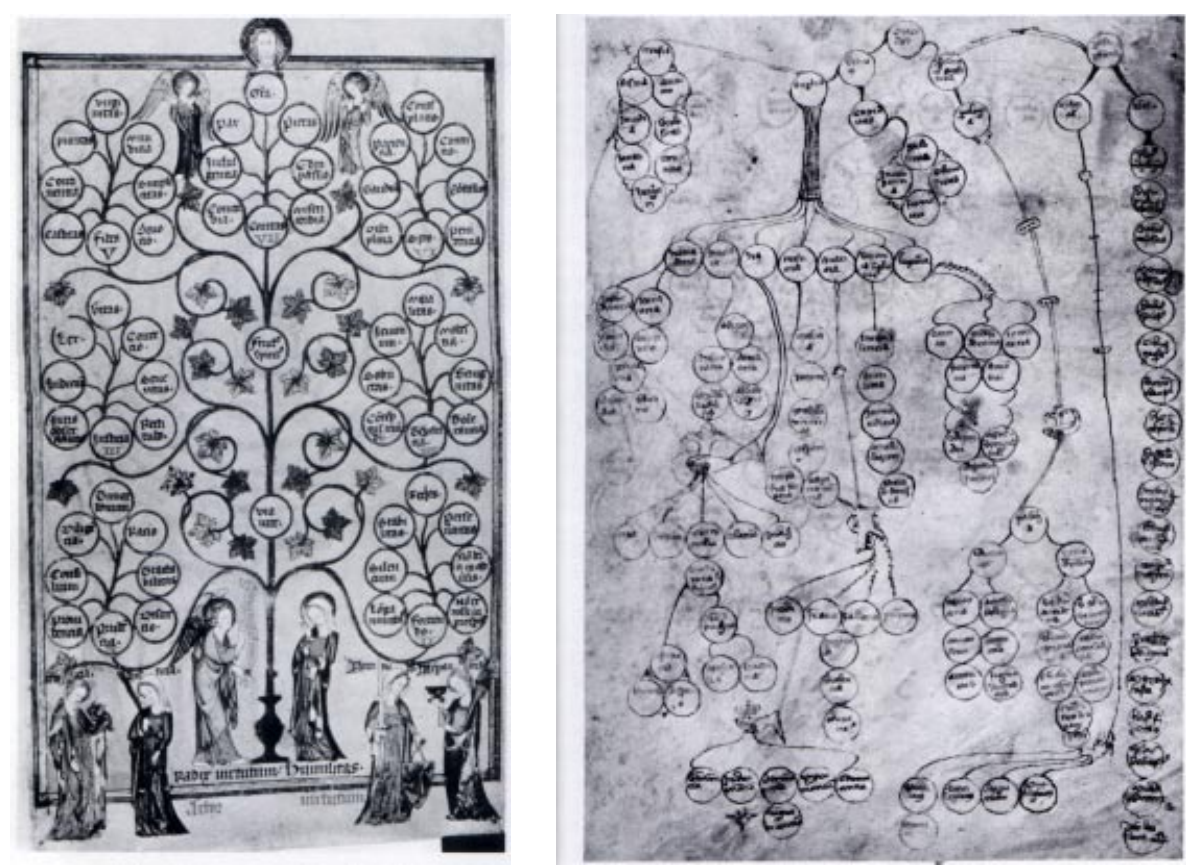

Fig. 4. A "Tree of Virtues" (Arbor Virtutum) and a "Tree of Vices" (Arbor Vitium), both from the 14th century. Reproduced with permission.

Although primarily used to illustrate arguments in logic, squares of opposition were also used in other fields during the Middle Ages. The drawing in Figure 7 illustrates the mathematics of musical intervals. It comes from an 11thcentury manuscript of Boethius's De Instituone Musica (23], p. 67).

Early graph drawing was not exclusively an invention of the Old World. Quipus consist of a series of variously colored strings attached to a base rope and knotted in ways that encode information idiosyncratically — see Figure 8 . They were used by the Incas from the 13th to 16th centuries for accounting purposes and to register important facts and events. Of the few hundred surviving examples, roughly $25 \%$ exhibit hierarchical structure [4] and therefore qualify as tree 


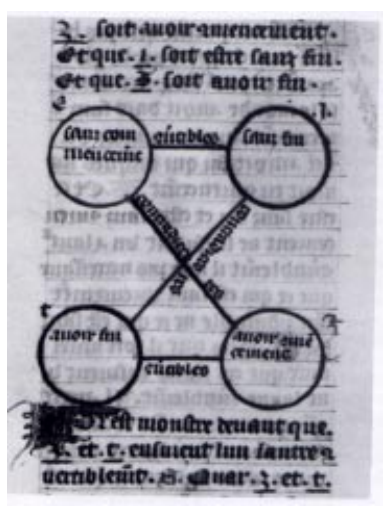

Fig. 5. A simple square of opposition from the 14th century. The nodes represent logical propositions. The edges represent relations between the propositions. Reproduced with permission.

drawings. However, nobody knows exactly what the nodes and edges represented in such graph drawings.

\section{Leonhard Euler and Graph Drawing}

One might expect the transition from early to modern graph drawing to be marked by Euler's famous paper in 1736 [12] on the path-tracing problem posed by the bridges of Königsberg. In this paper Euler solved the problem by introducing the concept of a graph comprising nodes and edges: 4 it marks the beginning of graph theory as a topic of study. The problem was brought to Euler's attention by his friend Carl Ehler in a letter dated March 9, 1736 [27]. Generalizing from his solution to this particular problem, Euler derived the first results in graph theory [20].

However, 1736 does not mark the beginning of modern graph drawing. Remarkably, in his study of the Königsberg Bridges problem Euler did not use graph visualizations to present or explain his results. Although two sketched maps of Königsberg (see Figure 9) are included in Euler's paper, no graph drawings appear there or anywhere else in his works.

An explanation for Euler's lack of interest in graph visualization can be found in the first paragraph of his paper. Euler began with a reference to Leibniz's (1646-1716) vision of a new kind of geometry without measurement or magnitudes. Leibniz's early discussion of what came to be called the geometria situs (and later topology) comes from his letter of September 8, 1679 to Huygens. In this letter Leibniz emphasizes the usefulness of a "new characteristic, completely different from algebra, which will have great advantage to represent to

\footnotetext{
${ }^{4}$ However, the term "graph" was not coined until 1878 by the English mathematician James Joseph Sylvester (1814-1897) [29.
} 


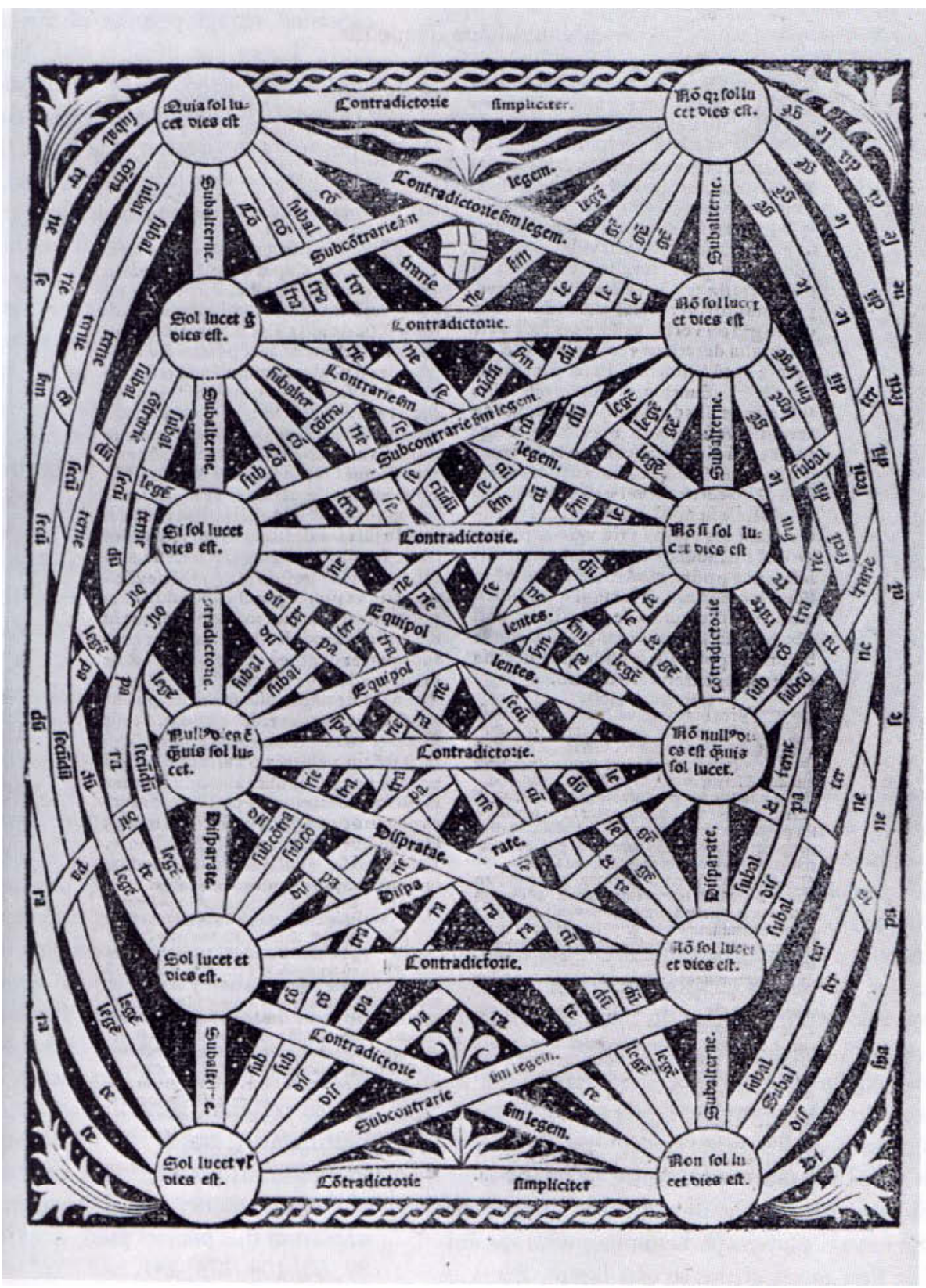

Fig. 6. A more complex square of opposition from the 16th century. It is a symmetric drawing of $K_{12}$ with labeled nodes and edges. Reproduced with permission. 


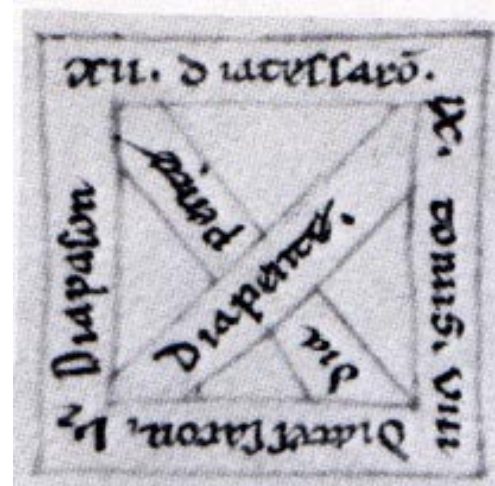

Fig. 7. Musical intervals drawn in a square of opposition from the 11th century. The nodes (corners) represent numbers and the edges represent named ratios between them (e.g., "octave" and "fifth"). Reproduced with permission.

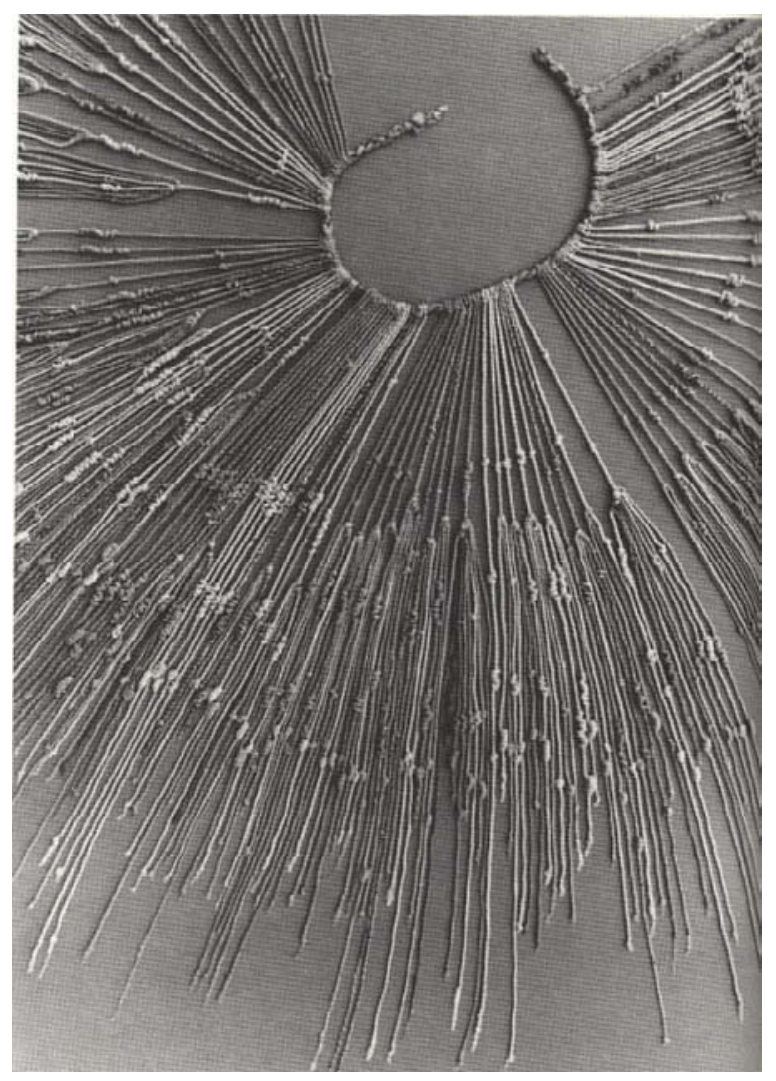

Fig. 8. A quipu in the collection of the Museo National de Anthropologia y Arquelogía, Lima, Peru [4. Reproduced with permission. 

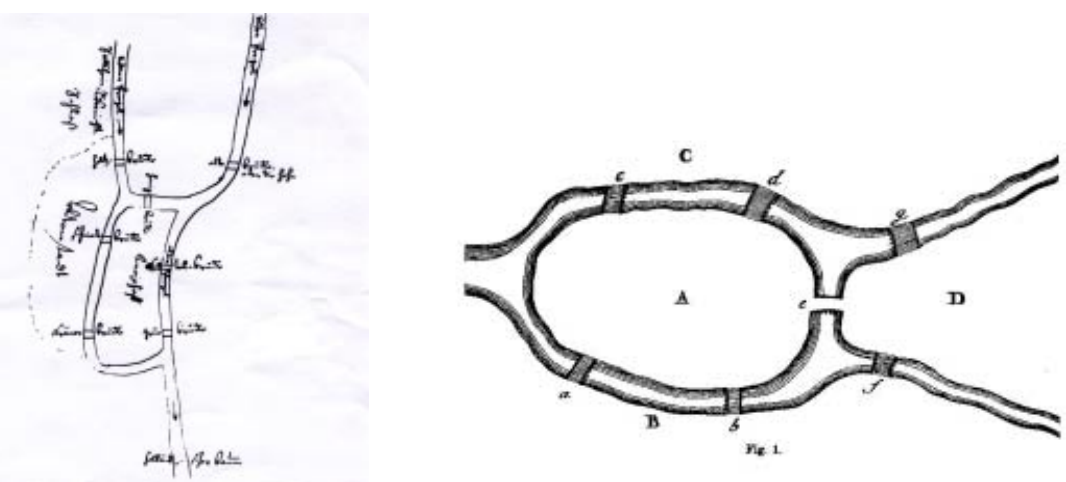

Fig. 9. Ehler's sketched map of Königsberg, 1736 (left), and Euler's more polished version 12. Euler included one more sketched map (a variant of the first with more bridges included) in his paper, but no abstract graph drawing of the problem. Reproduced with permission.

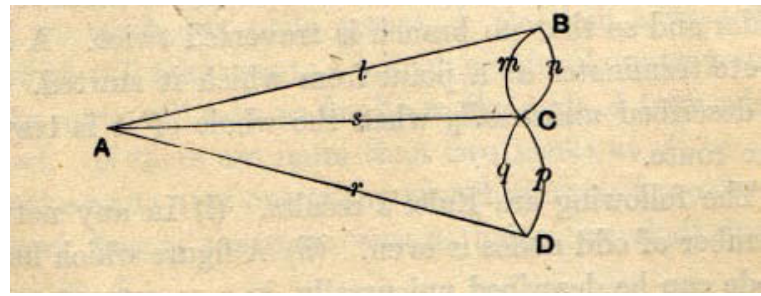

Fig. 10. Ball's 1892 graph-drawing abstraction of the bridges of Königsberg. The nodes represent the land areas and the edges represent the bridges connecting them. Reproduced with permission.

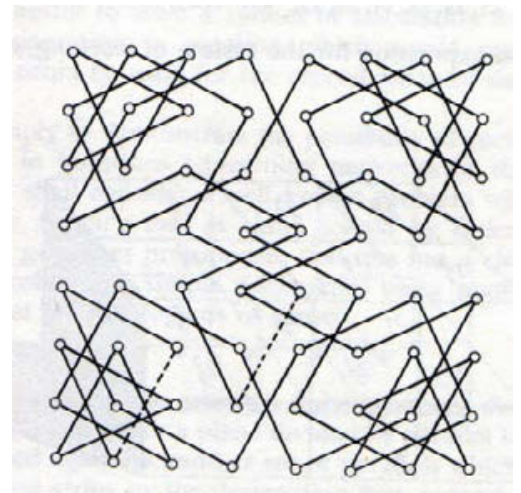

Fig. 11. Vandermonde's 1771 graph drawing of a Knight's Tour. This is actually a drawing of a subgraph of the graph that represents all possible knight moves. In that graph the nodes represent squares on a chessboard and edges represent legal moves. Reproduced with permission. 
the mind exactly and naturally, though without figures.5 everything which depends on the imagination" 21. Euler was probably familiar with a collection of Leibniz's correspondence because of his post at the Imperial Academy of St. Petersburg, with which Leibniz had been closely connected 16. Given Leibniz's conviction that his geometria situs would involve "neither figures nor models and would not hinder the imagination," Euler may well have been predisposed against the use of graphical visualizations to describe or solve graph-theoretic problems (even though he included geometric figures and function plots in many of his papers). It was probably not until 150 years later that W. W. Rouse Ball (1850-1925) drew the first abstract graph drawing that depicts the Königsberg Bridges problem [32]. Ball's graph drawing (see Figure 10) appeared in his 1892 book on mathematical recreations [5].

Another example of Euler eschewing the use of graph visualization is provided by his work in 1759 on another mathematical puzzle, that of computing a "Knight's Tour" on a chessboard [13]. This problem is to find a sequence of moves that takes a knight to each square of the board exactly once and returns it to its starting square. Twelve years later, in 1771, Vandermonde clarified the problem with a graph drawing [31] (see Figure [11). His inspiration for this drawing is very vivid: "if one supposes that a pin is fixed in the centre of each square, the problem reduces to the determination of a path taken by a thread passed once around each pin and following a rule whose formulation we seek" (translation from [7, p. 24).

\section{Early Examples of Modern Graph Drawing}

Although the transition from early to modern graph drawing did not coincide exactly with the invention of graph theory, it did follow shortly thereafter. Starting in the late 18th century and early 19th century, graph drawings began to appear more frequently and in more contexts. In mathematics, many papers were then illustrated with graph drawings:

- J.B. Listing (1808-1882) in his 1847 treatise on topology [22] devotes a short section to path tracing in graphs and includes the memorable drawing in Figure 12, which can be drawn in a single stroke.

- Sir William Rowan Hamilton (1805-1865) devised a game based on a noncommutative algebra that he dubbed the "Icosian Calculus." The gameboard consisted of a graph drawing — see Figure 13 Various games and puzzles could be played on this board [17].

- Arthur Cayley's (1821-1895) pioneering work on trees was illustrated with drawings like those in Figure 14 10.

Around the same time graph drawing also appeared in other fields, such as crystallography and chemistry. René Just Haüy (1743-1822) established the basic principles of crystallography. His abstract drawings of crystals represent a hybrid form of visual abstraction that is part geometric drawing and part three-dimensional graph drawing — see Figure [15] [18].

\footnotetext{
5 The italics are ours.
} 


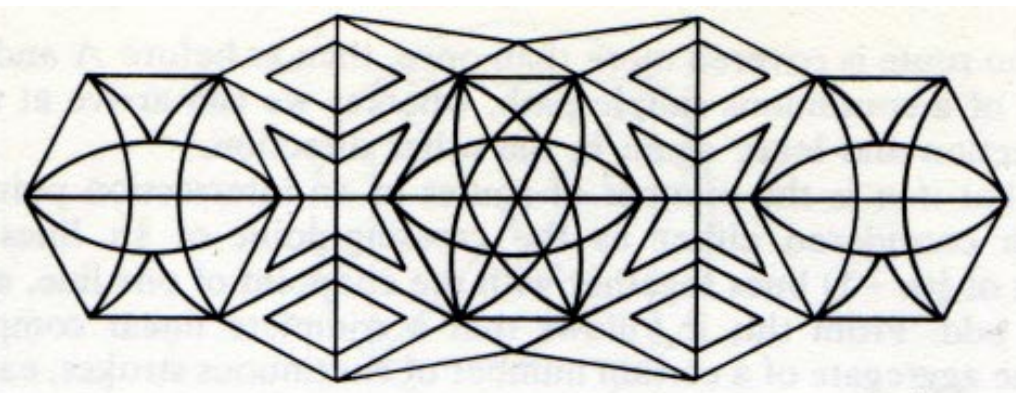

Fig. 12. A graph drawing from 1847 that can be drawn in a single stroke. Reproduced with permission.

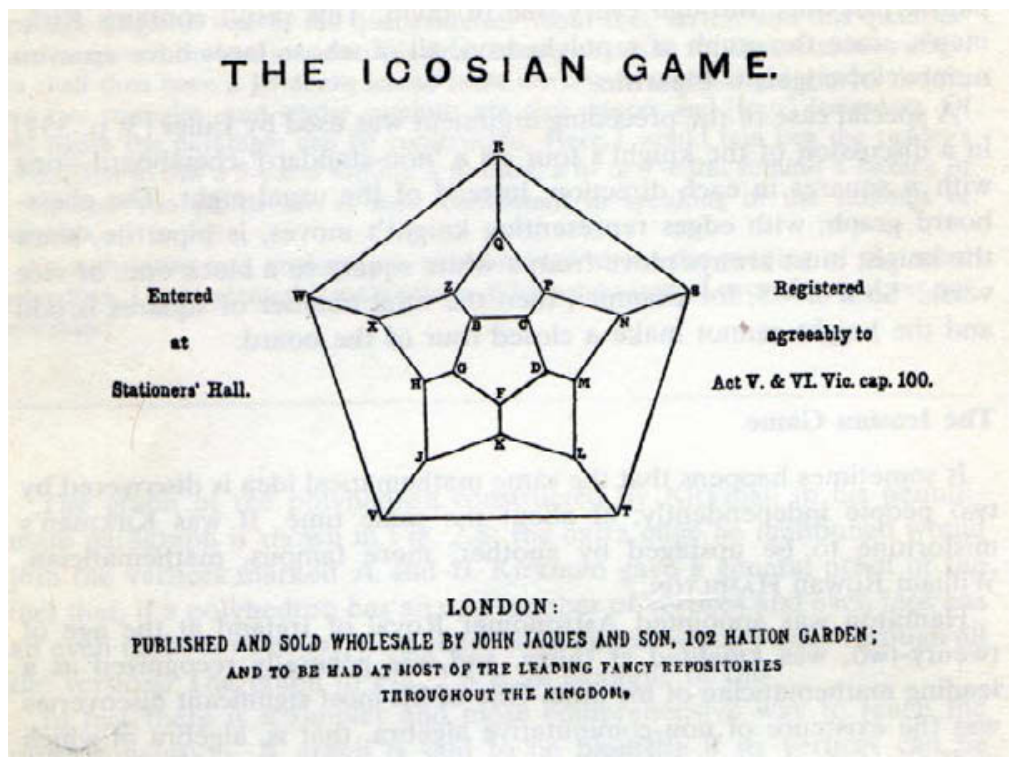

Fig. 13. Hamilton's Icosian Game from 1857. Reproduced with permission.
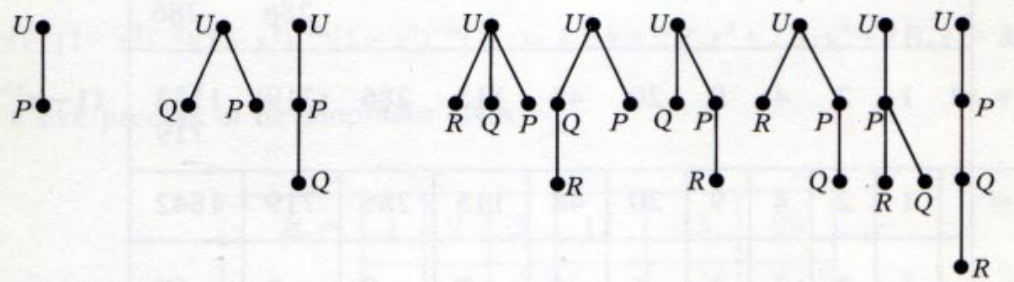

Fig. 14. Trees with labeled nodes from a 1857 paper of Cayley. Reproduced with permission. 


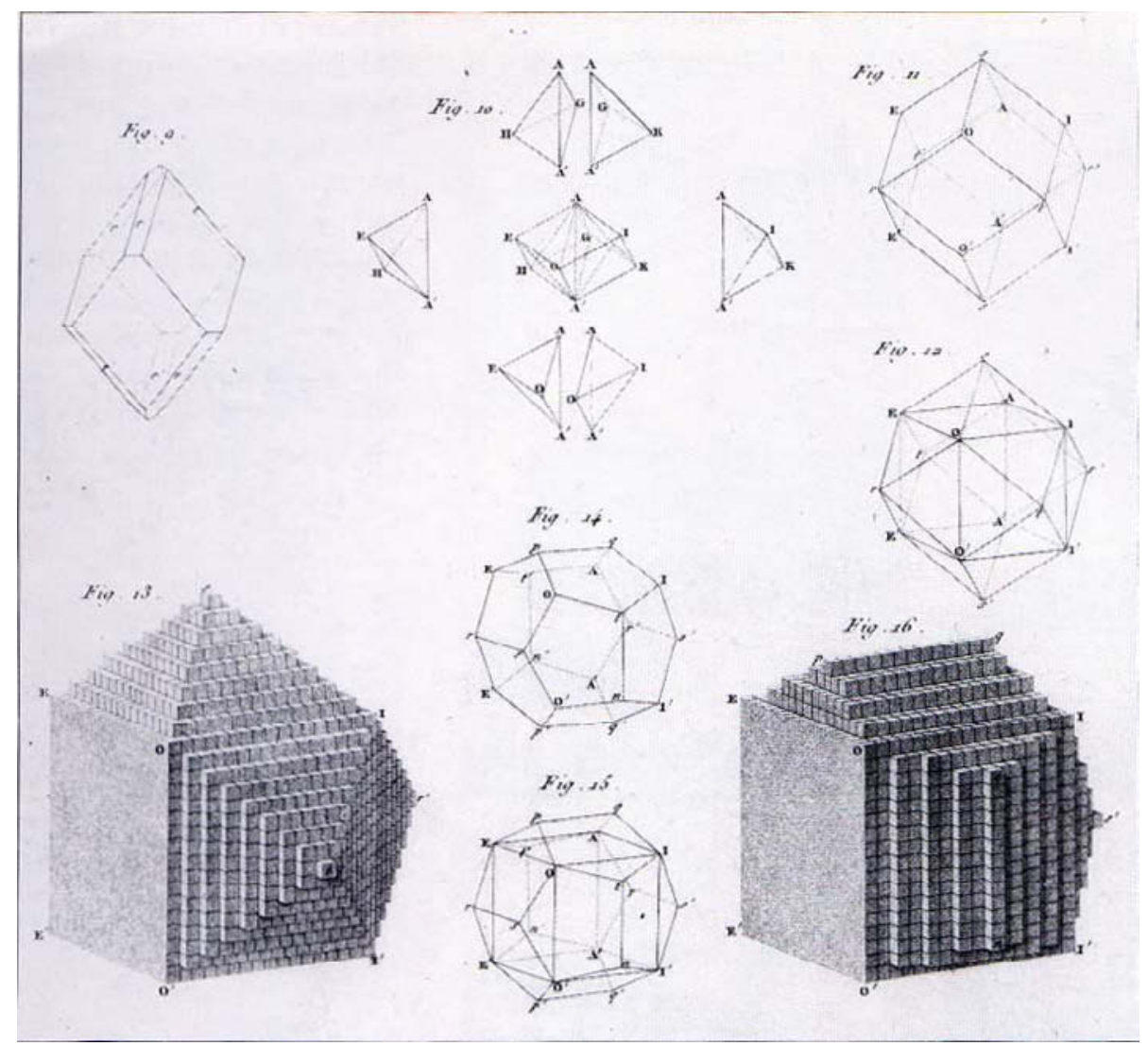

Fig. 15. Drawings from 1784 that depict the geometry of crystal structures but that also foreshadow the use of 3D graph drawing. The graph nodes correspond to corners or apexes of the physical crystal. Edges connect neighboring nodes. Reproduced with permission.

Depicting molecules as graph drawings may seem obvious now, but various other graphical depictions were proposed before Alexander Crum Brown (18381922) introduced the familiar drawings shown in Figure 16 9. The adoption of Brown's drawing conventions was greatly facilitated by their inclusion in popular lecture notes by E. Frankland 15.

\section{Conclusions and Future Work}

The main impetus for current research on computer-aided graph drawing is to facilitate the visual analysis of various kinds of complex networked or connected systems, e.g., computer networks, social networks, engineering systems, etc. In contrast, the drawings above show that the driving forces behind the initial development of graph drawing were pedagogy, exposition, record keeping, and 


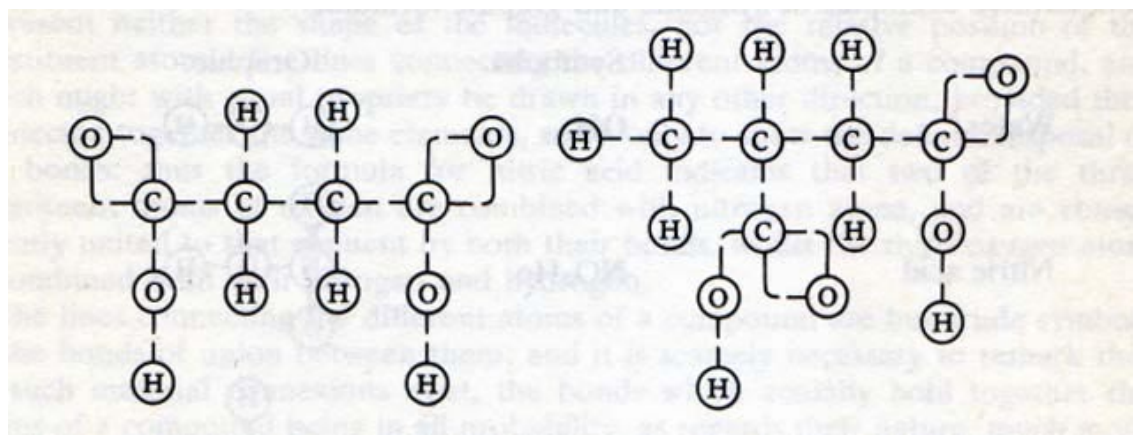

Fig. 16. Brown's 1864 depictions of two molecules as graph drawings. Modern drawings of molecules differ only slightly from this style: the circles around the atoms are usually omitted. This may be the first example of an orthogonal graph drawing, i.e., one in which the edges are only routed horizontally or vertically. Reproduced with permission.

mathematical recreation. That pedagogy and exposition should have created a need for graphical visualization is perhaps not unexpected; the same can be said of record keeping. However, the fact that mathematical recreation played a prominent role in the development of graph drawing is surprising. Although mathematical recreations have a long and interesting history [1511] — the extensive bibliography in [1] indicates clearly the rise in popularity of the topic from the 16th century onward - they have not been considered as having contributed significantly to mathematics. Nevertheless, the case of graph drawing shows that they were the locus of important innovation, particularly in the development of visual aids to solving problems.

We were also surprised to learn that Euler, the originator of modern graph theory, was not a pioneer in graph drawing: his study of graph theory seems to have been completely grounded in symbolic representations. Much as we might like to believe in the fundamental power of drawings to illuminate graph problems, it is clear that some people do not need such visualizations to have insights.

It seems likely that other examples of early modern graph drawing can be found in the literature of other disciplines, e.g., electrical engineering, abstract cartography. One subject for future work is an investigation of how graph drawing emerged in these fields.

Acknowledgments. We gratefully acknowledge the help of the following people: Peter Eades, Renee Hall, Darren Leigh, John Murdoch, Bob O'Hara, Nathaniel Taylor, Brian Tompsett, and the anonymous reviewers.

\section{References}

1. W. Ahrens. Mathematische Unterhaltungen und Spiele. Druck und Verlag Von B.G. Teubner, Leipzig, 1901. 
2. Alfonso X, King of Castile and Leon. Libros del ajedrez, dados y tablas. 13th century.

3. S. Ammirato. Alberi genealogici, late 16th century. Biblioteca Riccardiana, Florence, Grandi formati 33, No. 67. Reproduced in [19, Fig. 6.

4. M. Ascher and R. Ascher. Code of the Quipu: A Study in Media, Mathematics, and Culture. University of Michigan Press, Ann Arbor, Michigan, 1981.

5. W. W. R. Ball. Mathematical Recreations and Essays. The MacMillan Company, New York, 1939. 11th Edition. First published in 1892.

6. Beatus of Liebana. Commentary on the Apocalypse of Saint John, 11th century. Diagram from the Bibliothèque Nationale, Paris, (MS. Lat. 8878, fols. 6v-7r). Reproduced in 33], p. 331.

7. N. L. Biggs and L. Wilson. Graph Theory 1736-1936. Clarendon Press, Oxford, 1976. An excellent secondary source on the history of graph theory.

8. Boccaccio. Genealogia deorum, early 15th century. University of Chicago Library, Ms. 100, Tree VIII. Reproduced in [19], Fig. 22.

9. A. C. Brown. On the Theory of Isomeric Compounds. Transactions of the Royal Society Edinburgh, 23:707-719, 1864.

10. A. Cayley. On the Theory of the Analytical Forms Called Trees. Philosophical Magazine, 4(13):172-176, 1857.

11. M. Édouard Lucas. Récréations Mathématiques. Gauthier-Villars, ImprimeurLibraire, Paris, 1882.

12. L. Euler. Solutio Problematis ad Geometriam Situs Pertinentis. Commentarii Academiae Scientiarum Imperialis Petropolitanae, 8:128-140, 1736. Also in Opera Omnia (1) 7, 1923, pp. 1-10. An English translation can be found in [7], pp. 3-8.

13. L. Euler. Solution d'une Question Curieuse qui ne Paroit Soumise a Aucune Analyse. Mémoires de l'Académie des Sciences de Berlin, 15:310-337, 1759. Also in Opera Omnia (1) 7, 1923, p. 26-56.

14. B. J. Ford. Images of Science: A History of Scientific Illustration. Oxford University Press, New York, 1993.

15. E. Frankland. Lecture Notes for Chemical Students. London, 1866. An English translation can be found in [7], pp. 58-60.

16. C. C. Gillispie. Dictionary of Scientific Biography. Charles Scribner's Sons, New York, 1973.

17. W. R. Hamilton. The Icosian Game, instruction leaflet, 1859. A copy of this leaflet can be found in [7, pp. 32-35.

18. R. J. Haüy. Essai d'une théorie sur la structure des crystaux. 1784. A copy of the drawing can be found in [14], p. 137.

19. C. Klapisch-Zuber. The genesis of the family tree. In W. Kaiser, editor, I Tatti Studies: Essays in the Renaissance, Volume Four. Leo S. Olschki, Florence, Italy, 1991.

20. D. König. Theorie der Endlichen und Unendlichen Graphen. Akademische Verlagsgesellschaft M.B.H., Leipzig, 1936. Also available in English from Birkhäuser Boston, 1990.

21. W. G. Leibniz. Letter to Christiaan Huygens, September 8, 1679. In I. Gerhardt, editor, Leibnizens Mathematische Schriften, volume 2. A. Asher and Co., 1850.

22. J. B. Listing. Vorstudien zur Topologie. Göttinger Studien, 1:811-875, 1847. An English translation can be found in [7], pp. 14-16.

23. J. E. Murdoch. Album of Science - Antiquity and the Middle Ages. Charles Scribner's Sons, New York, 1984. An excellent secondary source for scientific illustration in ancient and medieval times. 
24. H. J. R. Murray. A History of Board Games Other Than Chess. Oxford University Press, Oxford, England, 1952.

25. H. Parker. Ancient Ceylon: An Account of the Aborigines and of Part of the Early Civilisation. Luzac \& Co., London, 1909.

26. W. Playfair. The Commercial and Political Atlas. London, 1786.

27. H. Sachs, M. Stiebitz, and R. J. Wilson. An historical note: Euler's Königsberg letters. Journal of Graph Theory, 12(1):133-139, 1988.

28. J. Stalham, late 15th century. English Public Records Office, Ref. No. REQ2/26/48. Thanks to Bob O'Hara for researching this and other documents on our behalf at the PRO.

29. J. J. Sylvester. Chemistry and Algebra. Nature, 17:284, 1877-8.

30. L. Tilling. Early experimental graphs. British Journal for the History of Science, 8:193-213, 1975.

31. A.-T. Vandermonde. Remarques sur les Problèmes de Situation. Histoire de l'Académie des Sciences (Paris), 1771. An English translation can be found in 7], pp. 22-26.

32. R. J. Wilson. An Eulerian trail through Königsberg. Journal of Graph Theory, 10(3):265-275, 1986.

33. D. Woodward. Medieval mappaemundi. In J. B. Harley and D. Woodward, editors, The History of Cartography, Volume 1: Cartography in Prehistoric, Ancient, and Medieval Europe and the Mediterranean. The University of Chicago Press, Chicago \& London, 1987.

34. Chronica regia coloniensis, 1150-60. Herzog August Bibliothek, Wolfenbüttel, Cod. Guelf. 74. 3 Aug. 2nd. Reproduced in [19, Fig. 3.

35. http://www .ahs. uwaterloo.ca/ museum/vexhibit/board/rowgames/mill.html. 